\title{
Interface Gráfica Para Leitura e Escrita na Formação Docente
}

\author{
Graphical interface for reading and writing in teacher education
}

\author{
Wilton James Bernardo-Santos* \\ *Universidade Federal de Sergipe, UFS, São Cristóvão - SE, 49000-100, e-mail: \\ wjames@uol.com.br
}

\begin{abstract}
RESUMO: A partir de um projeto mais amplo, este trabalho apresenta uma síntese de reflexões teóricas e princípios de procedimentos práticos básicos para formação docente, focalizando o ensino-aprendizagem de leitura e escrita no Ensino Médio no Brasil. Apresentamos um breve histórico da produção acadêmica, após a redemocratização dos anos de 1980/90 e comentamos alguns tópicos propostos pelas políticas públicas. Destacamos especificidades da escrita como instrumento tecnológico, decisivas para leitura e produção de textos. Por fim, apresentamos duas práticas de leitura a partir de procedimentos metodológicos para o tratamento gráfico de textos. O objetivo é colocar o leitor em condições de compreender os processos de construção de texto na posição da autoria. Tais práticas mobilizam sentidos de "jogo" que afetam o leitor nas relações da língua com a escrita enquanto interface gráfica e instrumento analítico.
\end{abstract}

PALAVRAS-CHAVE: Leitura, Escrita; Ensino Médio.

ABSTRACT: From a broader project, this paper presents a synthesis of theoretical reflections and principles of basic practical procedures for teacher training, focusing on teaching and learning of reading and writing in High School in Brazil. We present a brief history of the academic production, after the redemocratization of the years 1980/90 and we comment some topics proposed by the public policies. We emphasize writing specificities as a technological instrument, decisive for reading and producing texts. Finally, we present two reading practices based on methodological procedures for the graphic treatment of texts. The goal is to put the reader in a position to understand the processes of text construction in the position of authorship. Such practices mobilize "game" senses that affect the reader in the relations of language with writing as a graphic interface and analytical instrument.

KEYWORDS: Reading, Writing; High school.

\section{INTRODUÇÃO (HISTÓRIA: A REDEMOCRATIZAÇÃO)}

No Brasil dos anos de 1990, a "questão da escrita", sobretudo na elaboração de trabalhos acadêmicos, sempre esteve no centro das preocupações. Interferem nos processos de leitura e de escrita: a língua padrão, a linguagem adequada, problemas enunciativos, de ordem discursiva e de diferentes sistemas semióticos. A dimensão gramatical e o estudo dos usos da língua foram colocados em seus devidos lugares, ou 


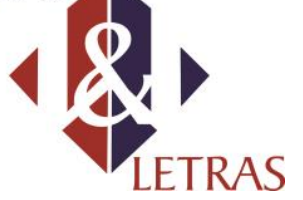

e-ISSN: $1981-4755$

DOI: $10.5935 / 1981-4755.20170004$

seja, a reflexão sobre a língua, a análise para o monitoramento de suas regularidades não como um fim ensimesmado, mas como um meio instrumental, parte das práticas de leitura e de escrita. As ciências da linguagem, notadamente a Linguística, propunham uma ruptura com as chamadas gramáticas normativas escolares. Segundo Possenti (1996), é preciso considerar gramáticas descritivas dos usos da língua e ainda a gramática internalizada.

Obviamente que, de modo decisivo, no Brasil, com a chegada da internet, do hipertexto como nos ensinam Carvalho (2006) e Marcuschi (1999), as práticas de leitura e de escrita foram favorecidas, mas notemos que são atividades diversas daquelas demandadas pela produção do conhecimento acadêmico, segundo Autor (2015). O conhecimento científico requer leitura e escrita com textos um pouco mais longos (não ficção em função referencial da linguagem informativa) no Ensino Médio. Nesse sentido, o trabalho de formação docente na área de Letras tem se deparado com entraves. As questões linguísticas do domínio da frase, do período, do parágrafo, em fim, do texto verbal são "ainda" fundamentais para as demandas básicas da produção científica: elaboração de resumos, resenhas, relatórios, artigos etc.

Nessa trajetória, é preciso considerar abordagens pragmáticas bem anteriores que tratam o sujeito em suas relações com o mundo já a partir de trabalhos básicos, sobre identidade e referência, com Frege (1978) e também os sentidos da intenção do falante, com Grice (1957). Nessa direção, interessam os estudos elementares sobre pressuposição, a partir de Ducrot (1972; 1987), e enunciação Benveniste (1966; 1974). Esse trajeto inclui o que no Brasil se convencionou chamar de Semântica Argumentativa, com Vogt (1977; 1980) e Guimarães (1989; 1995).

Vem também a decisiva concepção do sujeito como descentrado e constituído em condições de produção históricas específicas. É a contribuição da Análise do Discurso, uma proposta de ruptura metodológica e fragmentação da noção de autoria, tendo em vista as formulações de Foucault (1969a, 1969b). De modo decisivo temos as noções de interdiscurso e formação discursiva de Pêcheux (1998) e reunidas por Gadet \& Hak, (1997).

De outra forma, como parte do movimento histórico, esse processo de abertura teórico-metodológica aparece legalmente contemplado. A Lei de Diretrizes e Bases da Educação Nacional - LDB, Lei no 9.394/96, Lei no 9.394/96, estabeleceu como sendo dever do Estado garantir "o desenvolvimento da capacidade de aprender, tendo como meios básicos o pleno domínio da leitura, da escrita." Entre as finalidades do Ensino 


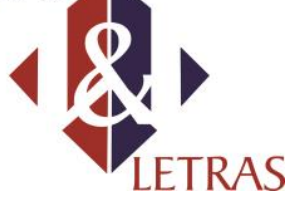

e-ISSN: $1981-4755$

DOI: $10.5935 / 1981-4755.20170004$

Médio, etapa final da educação básica, aparece o "desenvolvimento da autonomia intelectual e do pensamento crítico" e ainda propõe que o educando demonstre "conhecimento das formas contemporâneas de linguagem". ${ }^{1}$

No que toca especificamente o ensino da língua portuguesa, tomar consciência e aprimorar o controle sobre a própria produção linguística são os objetivos gerais traçados pelos Parâmetros Curriculares Nacionais-PCN (1997). Ou seja, "usar os conhecimentos adquiridos por meio da prática de reflexão sobre a língua para expandirem as possibilidades de uso da linguagem e a capacidade de análise crítica". ${ }^{2}$

E isso só aparece como possível se a mudança também inclui um duplo deslocamento: do estudo da frase em direção à produção de textos e de um estruturalismo imanente em direção a concepções teóricas de linguagem e, portanto, de texto, capazes de incluir como objeto de estudos: a sociedade, o sujeito, a história. Assim, no documento oficial, vem, entre outras, a noção de Gêneros do Discurso a partir de Bakhtin, (1953; 1998) que se tornou dominante, segundo Autor (2009), o chamado Sócio-interacionismo com Bronckart (1999), a Linguística textual com Kock (1994, 1998), o decisivo Letramento com Kleiman (1995) e Tfouni (2010) e a Análise do Discurso com Orlandi (1985; 1988; 1996).

No fundo, os documentos oficiais propuseram uma ruptura de tal ordem que produziram as mais variadas incompreensões junto aos professores da Educação Básica. Por exemplo, na publicação do MEC, as práticas de reflexão sobre a língua dizem respeito a atividades classificadas em epilinguísticas e metalinguísticas com Geraldi (1991). O problema é que desses princípios, a proposta de ensino subrepticiamente desliza para uma maquinaria comunicacional de revisão de textos, impedindo o trabalho de avançar em direção a gestos autorais. De sorte que se instalou na realidade cotidiana do ensino uma verdadeira crise da noção de texto, segundo Autor $(2001 ; 2002)$.

Mas, por outro lado, a proposta deslocou a materialidade do objeto de estudos. Há, por exemplo, toda uma produção acadêmica que bem demonstra esse momento histórico, basta uma visada nos trabalhos dedicados à linguagem oral com Koch \& Marcuschi (1998) e Ilari (2001) e à interface oralidade/escrita novamente com Marcuschi (2001). Nessa mudança, também a referência é deslocada de certa literatura

\footnotetext{
${ }^{1}$ Pela ordem: Seção III, art. 32, I. Seção IV, art. 35, III. E, por fim, art. 36, § $1^{\text {o }}$, II. Disponível no site do MEC: http://www.planalto.gov.br/ccivil_03/Leis/L9394.htm.

${ }^{2}$ Brasil, Secretaria de educação Fundamental. Parâmetros Curriculares Nacionais: língua portuguesa, 1997, p. 42.
}

Volume 18

Número 39 


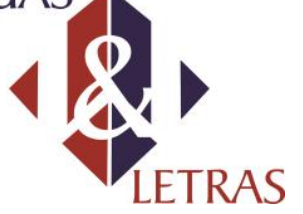

e-ISSN: $1981-4755$

DOI: $10.5935 / 1981-4755.20170004$

canônica e arcaica, para produções de autores contemporâneos, e, sobretudo, para a imprensa, os jornais (impressos e digitais).

Trabalhando com textos acadêmicos e jornalísticos (impressos e digitais), consideramos a escrita em suas formas materiais, sua natureza tecnológica empírica, espacial, bidimensional, visual com formulado por Auroux $(1992$; 1998) e os efeitos da projeção, da sobreposição e da integração de sentidos, a partir de Guimarães (2002). Também são decisivos o modelo Y e a categoria de análise X, com Autor (2008; 2014). ${ }^{3}$ Eis os domínios da autoria nas práticas de leitura e de escrita para o ensino, com Tfouni (2008), Fiad (2008) e Possenti (2001; 2002). Comentemos alguns pontos propostos pelas políticas públicas.

\section{TÓPICOS DAS POLÍTICAS PÚBLICAS}

Evidentemente que o universo da escrita está implicado em uma ampla variedade de tópicos: a localização de informações explícitas, a inferência de sentidos, identificação de temas e a "posição do autor" como estão descrito, por exemplo, na Matriz Referência de Língua Portuguesa do Mec. ${ }^{4}$ Dos seis tópicos apresentados, três deles nos interessam mais de perto. Faço abaixo alguns comentários que os ajustam na direção das práticas efetivas de leitura e de escrita.

O tópico II propõe o estudo das "Implicações do Suporte, do Gênero e /ou do Enunciador: interpretar texto com auxílio de material gráfico diverso (propagandas, quadrinhos, foto, etc.) e identificar a finalidade de textos de diferentes gêneros". Apesar de ser relevante o tópico, penso que nas práticas escolares, abriu-se muito espaço para linguagens não verbais no ensino da língua. Com isso, os livros didáticos e demais materiais do ensino privilegiam códigos. Ocorre que, apesar de as pesquisas terem avançado na área, as especificidades de tais códigos não são ainda adequadamente trabalhadas pelas licenciaturas e, nesse caso, o ensino parece ainda operar pelo senso comum.

O tópico III traz a "Relação entre Textos: diferentes formas na comparação de textos que tratam do mesmo tema, em função das condições de produção e recepção"; e "posições distintas relativas ao mesmo fato ou ao mesmo tema". As relações entre

\footnotetext{
${ }^{3}$ Para evitar a identificação da autoria, optamos por essas descrições mais abstratas: modelo Y e a categoria de análise $\mathrm{X}$.

${ }^{4}$ Encontramos o conjunto dos tópicos em:

<http://www.inep.gov.br/basica/saeb/matrizes/topicos_descritores_port.htm>

Volume 18

Número 39
} 


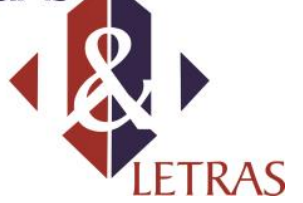

e-ISSN: $1981-4755$

DOI: $10.5935 / 1981-4755.20170004$

textos e as posições construídas precisam ser consideradas nas condições enunciativas da situação imediata de comunicação (o eu/tu - aqui/agora). Por outro lado, propomos que as práticas de leitura e de escrita sejam orientadas também para a compreensão das condições sócio-históricas de produção, pelo caráter material dos sentidos, a partir de Pêcheux (1998) e Orlandi (2001). Ou seja, os sentidos, a memória que afeta e constitui a posição sujeito. Por exemplo, um mesmo fato é noticiado de diferentes modos e diferentes posições são construídas se são diferentes os meios: os jornais x, y ou z. O tema e o fato são os mesmos, mas as relações entre textos trazem as contradições e os antagonismos próprios das sociedades.

O tópico IV propõe "Coerência e Coesão no Processamento do Texto: estabelecer relações entre partes de um texto, identificando repetições ou substituições que contribuem para a continuidade de um texto". Nesse ponto, evitamos certo tratamento metalinguístico que lamentavelmente se propagou no ensino. O tópico propõe que trabalhemos para "estabelecer relação causa/consequência entre partes e elementos do texto; estabelecer relações lógico-discursivas presentes no texto, marcadas por conjunções, advérbios etc”. Essas relações são obviamente fundamentais, mas não devemos restringir as práticas de leitura à mera identificação de "operadores linguísticos" de coesão, por exemplo. Nessas práticas, o texto é usado tão somente como um "depósito" para identificação do que é adversativo, consecutivo etc. Em princípio, o aluno do ensino médio não será gramático ou linguista! (na seção seguinte, apresentamos princípios para a conduta do leitor no tocante à escrita).

O tópico IV também propõe "identificar a tese de um texto; estabelecer relação entre a tese e os argumentos oferecidos para sustentá-la”. Esse ponto é central, mas é preciso dar ênfase ao modo de trabalhar, ou seja, a metodologia empregada para o alcance desse objetivo; além de considerar aspectos ideológico-discursivos na construção da posição do sujeito. Outra proposta do tópico é "Diferenciar as partes principais das secundárias em um texto". Nessa questão, devemos trabalhar no sentido de problematizar essa hierarquização estruturante. Outro ponto do mesmo tópico é "Identificar o conflito gerador do enredo e os elementos que constroem a narrativa". A meu ver, esse enunciado marca de certa forma a preponderância de textos narrativos no ensino.

Bem, os tópicos são interessantes e realmente representam proposta de mudança no ensino, mas os problemas básicos em relação à leitura/escrita persistem. As pesquisas divulgadas, inclusive as mais recentes, nos dizem das "deficiências dos 


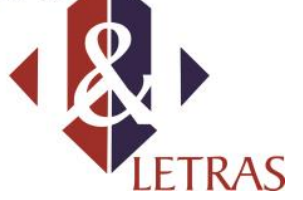

e-ISSN: $1981-4755$

DOI: $10.5935 / 1981-4755.20170004$

alunos" que vão se acumulando ao longo dos anos e "se agravam" no Ensino Médio e, claro, não deixam de existir no Ensino Superior.

Como se vê, há um hiato tripartite entre a variada produção acadêmica, o que é eleito pela política pública para figurar como referência nos documentos oficiais do ensino e os efeitos produzidos nas praticas das aulas de leitura e de escrita. Obviamente que o que se produz na universidade é bastante variado e, claro, os professores da Educação Básica têm diferentes formações e o alunado também não é homogêneo em suas práticas. Mas, ora, se o problema não pode e nem deve ser apenas linguísticonormativo, ou mesmo de adequação da linguagem, já que textualizamos muito bem fora da norma, oralmente, por exemplo. Então, qual é o entrave maior?

O problema da leitura/escrita deve ser levado a domínios mais específicos. Nesse sentido, temos proposto tratamento adequado aos materiais efetivos das aulas. $\mathrm{O}$ centro de interesse deve ser a articulação entre as noções de escrita, autoria e textualidade a partir da categoria X como norteadora das práticas leitura/escrita. Vejamos então resumidamente alguns pontos importantes.

\section{ESCRITA: INSTRUMENTO TECNOLÓGICO PARA LER E ESCREVER}

Se a textualidade acontece no "estabelecimento de relações de sentido entre diferenças”, segundo Autor (2014). Se devemos trabalhar para que o alunado alcance a “capacidade de aprender", é preciso reconhecer que diferentes dimensões interferem na constituição do sujeito: língua padrão, linguagem adequada, enunciação, discurso etc. Essas dimensões não são pontos de chegada. Assim, o sujeito (professor e aluno) deve se colocar em posição de domínio dessas dimensões para avançar em suas construções no conhecimento. Nesse sentido, é óbvio que estamos diante de uma questão de domínio, de ordem instrumental.

O domínio dessa ordem parece ser o local de trabalho para a construção da "autonomia intelectual". Nessa direção, três dimensões são fundamentais:

a) Escrita (e textualidade) como dimensão instrumental tecnológica básica com especificidades próprias: visual e espacial.

b) Linguagem verbal onde o sujeito se inscreve em relações com outros objetos semióticos aos quais a própria a escrita vai se juntar. 
e-ISSN: 1981-4755

DOI: 10.5935/1981-4755.20170004
b) Autoria que é uma dimensão construída discursivamente precisa ser considerada nas condições de produção.

Destaquemos o item (a). A escrita é um instrumento tecnológico que estabelece relações com diferentes códigos e linguagens: a matemática, a geometria, por exemplo. Desse modo, a escrita e seu caráter empírico, sua espacialidade, sua bidimensionalidade, segundo Auroux (1992; 1998), interferem na relação com a língua. Por exemplo, os efeitos da projeção de sentidos próprios da categorização dos espaços em um volume/livro escrito. Os efeitos da sobreposição de sentidos por conta de ser a escrita o lugar enunciativo. As relações de sentido específicas da noção de integração não segmental. Aspectos que intervém na textualidade, na enunciação, nos efeitos de sentido entre locutores, com Guimarães (2002).

Tecnicamente a escrita é visual. Seu caráter espacial é o que a diferencia da oralidade. Sem o domínio da demarcação territorial, o leitor não opera pela função referencial da linguagem informativa escrita porque está tomado pelo falatório, pela oralidade da língua. Com isso, escapam os sentidos próprios da materialidade escrita. Também o leitor que não considera as especificidades da escrita se afasta do que propõe o autor, ou seja, é um leitor que não tem o domínio racionalizado do que está posto empiricamente na linearidade gráfica do texto, segundo Autor (2015). O que torna possível o esforço de compreensão é o sujeito tomar a escrita enquanto instrumento das práticas de ler e de escrever.

Dessa forma, é possível dizer que leitura-escrita é, em parte, um problema de ambientação. Por isso, pensamos que o domínio das práticas básicas de leitura de textos de não ficção um pouco mais longos deveria ter lugar central no Ensino Fundamental e Médio. Salvo exceções, textos longos, na Educação Básica, temos apenas os literários, onde o tempo/narrativa é preponderante. Ora, precisamos de formação também para a leitura e escrita científicas. Nesse caso, o preponderante não é a subjetividade da narrativa ficcional; é a objetividade da descrição estruturada.

Nesse sentido, em relação a escritos científicos, a academia historicamente preza o modelo Y, novamente com Autor (op. cit.). Por exemplo, um livro que divulga um conhecimento acadêmico/científico produzido tem uma forma material histórica: capas, prefácios, notas, introdução, capítulos, conclusão posfácio etc. Mas, seja qual for sua dimensão, o escrito científico guarda relações entre região introdutória, central, conclusiva e regiões periféricas. Tendo em vista essa natureza espacial, diante de um 


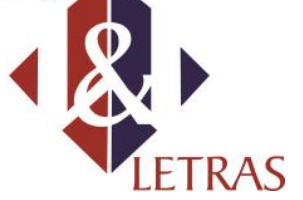

e-ISSN: $1981-4755$

DOI: $10.5935 / 1981-4755.20170004$

volume teórico, de um ensaio, de um tratado antropológico, de uma resenha, ou de uma reportagem publicada em jornal, propomos condutas ao leitor-analista-estudioso, a partir da categoria teórico-metodológica X. Ou seja, em resumo, ler é intentar o domínio das relações com a língua em deslocamento no espaço da escrita; escrever é construir espaço para deslocamento, no nosso caso, com objetividade.

De posse desse instrumento, o leitor considera os encaminhamentos marcados pelo autor no processo submetido à linearidade gráfica. Isso significa que se estamos nas primeiras linhas de um escrito, precisamos lê-las enquanto tais, enquanto lugar introdutório. Esse lugar é uma passagem que nos conduz de diferentes modos à razão de ser daquela unidade: seja ela um livro, um capítulo, um artigo, uma reportagem etc. $\mathrm{Na}$ introdução, estamos sendo levados a um lugar reservado para a "razão de ser" daquele escrito, daquele texto. De modo semelhante, devemos considerar as últimas linhas enquanto lugar que nos conduz à saída da "razão de ser" daquela unidade. A questão é que nem todo texto traz marcadas essas regiões com as palavras introdução e conclusão.

De qualquer forma, deve o leitor considerar, compreender e analisar os efeitos de sentido produzidos por essas regiões que, digamos, "não são efetivamente" o texto: apenas nos levam e nos retiram da região central da unidade. É tanto que nunca começamos e finalizamos um texto; começo e fim são efeitos produzidos, segundo Orlandi (2001). Os sentidos do início e do fim são puro efeito da linearidade a que o leitor/escritor está submetido, mas que precisa ser considerada, mesmo que a análise desconstrua o processo quebrando o real linear para dar acesso a espacialidades enunciativas e discursivas.

A partir de certa categoria de análise X, essa conduta teórico-metodológica deve ser geral já que a escritura é sempre um eterno retorno. De modo que também aquilo que o texto nos expõe como central traz inescapavelmente trechos introdutórios, conclusivos e centrais: um capítulo tem começo, centro e fim, por exemplo. Dessa forma, a categoria $\mathrm{X}$ deve operar não apenas na esfera global, nas relações entre grandes regiões do texto escrito e entre diferentes escritos. A categoria deve operar junto a trechos, passagens e zonas como introdução e conclusão, nas relações entre elas, mas também em seus interiores, no espaço dos parágrafos, já que os domínios do período e da frase são também um problema de ordem espacial, ver Moreno (2009). O ponto parágrafo, o ponto, a vírgula, o "ponto continuando", o ponto-e-vírgula etc: tudo isso é realização da escrita. 


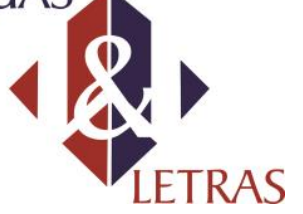

e-ISSN: $1981-4755$

DOI: $10.5935 / 1981-4755.20170004$

A partir desse processo de leitura, é possível compreender concretamente que a elaboração de um texto escrito parte de uma "centralidade analítica", um ponto específico que é trabalhado, decomposto, descrito etc. Em seguida, escrevemos a respeito desse escrito. Conduzimos o leitor a ele e dele o retiramos.

Em resumo, quando lemos e escrevemos, estamos em relação direta com a natureza espacial da escrita interferindo nos processos de significação da língua. A escrita é o instrumento empírico básico, não exclusivo, de que dispomos para trabalhar. Assim, é fundamental que tenhamos suas possibilidades bem à mão. A partir de procedimentos preliminares, vejamos agora duas práticas de leitura.

Na próxima seção, temos um percurso que conta com o que já foi arrolado até então, mas trazemos algumas poucas considerações e procedimentos básicos para a realização de duas práticas introdutórias em um curso de leitura e de escrita para o Ensino Médio.

\section{LABORATÓRIO: ANÁLISE E TRATAMENTO DE MATERIAIS}

Como sabemos, para a realização de quaisquer propostas em sala de aula, antes de tudo, é preciso priorizar os fundamentos do ofício nas condições contemporâneas: a articulação entre teorias específicas às práticas em sala de aula.

Além do repertório de bons textos que todos nós vamos construindo ao longo da carreira, quando estamos diante de um novo trabalho, é preciso, inicialmente, fazer um levantamento das características socioculturais dos alunos, a partir dos textos que circulam na própria escola e em práticas extraescolares lugares onde de modo específico leitura e escrita estão presentes na vida dos alunos em outras instituições (Família, Igreja, Trabalho, Mídia etc). Em fim, é preciso considerar a região, a cidade, o bairro, a localidade da escola. A orientação é construir arquivos de textos (impressos e digitais) que circulam socialmente e alcançam o alunado. ${ }^{5}$

Isso porque a efetiva produção do "pensamento crítico" em ciência nos impõe a documentação como método mais adequado a ser desenvolvido ao longo da vida acadêmica, por exemplo, a partir de Severino (2002) e, claro, ao longo da efetiva carreira do profissional docente. A partir da montagem de arquivos em práticas constantes, é possível abrir caminho para avançar na produção criativa do

\footnotetext{
${ }^{5}$ Obviamente que também é preciso considerar o projeto político-pedagógico da escola, os princípios de planejamento, de avaliação etc.
}

Volume 18

Número 39 


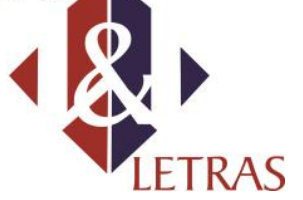

e-ISSN: $1981-4755$

DOI: $10.5935 / 1981-4755.20170004$

conhecimento. Com o repertório quantitativamente avançado de textos analisados, o profissional iniciante vai particularizando qualitativamente seu acervo, diante de diversos fatos de textualidade, de linguagem e de discurso. É estratégico que o acervo (impresso e digital) inclua textos especificamente acadêmicos de revistas especializadas, mas também publicações do chamado jornalismo cultural, ver Piza (2003) tendo em vista a forte presença intelectual na impressa permitindo uma boa discussão sobre as especificidades acadêmicas e jornalísticas, considerando Melo (1985); Kotho (1986) e Coimbra (1993).

Para finalizar o artigo, apresentamos duas práticas introdutórias em um curso de leitura e de escrita em função referencial da linguagem informativa para o Ensino Médio. Essas práticas devem ser precedidas da apresentação de especificidades da escrita, como já o dissemos, a partir da categoria de análise e de um modelo Y, Autor (op. cit.) e do fundamento do texto enquanto processo que estabelece "relações de sentidos entre diferenças".

\section{PRÁTICA I: O TODO: EM BUSCA DAS PARTES PERDIDAS}

Para esta prática, selecionamos uma resenha acadêmica: "Faces da escravidão: a escravidão no Brasil, na América Latina e na África" de Carvalho (2004). Antes da aula, um primeiro passo é dar um tratamento gráfico empírico para desfazer a paragrafação do texto. Ou seja, apagar todos os "pontos parágrafo" do texto. Com isso, o leitor tem frases e períodos, mas não tem marcas que identifiquem os parágrafos. Tem apenas uma sequência linear de três páginas em um bloco uno fechado. Nessas condições, o leitor é colocado diante do problema da indistinção entre diferenças e, ao mesmo tempo, é levado à posição de uma leitura autoral já que é preciso interferir na textualidade para buscar as diferenças.

Já no início da aula, trazemos um procedimento próprio da escrita, bastante aplicado no ensino, mas que não é apresentado como instrumento das práticas de leitura e de escrita. Estamos falando da numeração das linhas (de cinco em cinco) e dos comentários que fazemos às margens dos textos. São procedimentos da produção do conhecimento acadêmico científico: é o princípio do fichamento, base de construção do resumo. Ou seja, é com a escrita que materializamos análises de textos.

Bem, em seguida, mobilizamos a efetiva busca por diferentes unidades no interior daquela totalidade. É o momento em que vamos à procura dos sentidos de 


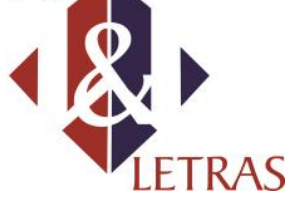

e-ISSN: $1981-4755$

DOI: $10.5935 / 1981-4755.20170004$

rupturas. As fraturas produzidas pelos gestos analítico-interpretativos da autoria. Ou seja, em sentido clássico mais estrito, mobilizamos um processo analítico que é a decomposição de um todo em suas partes constitutivas na busca das relações de sentido entre diferenças. Assim, paulatinamente, alfabetando essas unidades menores, os parágrafos, vamos efetivando as demarcações em trechos, zonas, áreas, centro e periferias daquele território.

Feito esse percurso, é possível então trabalhar com espaços maiores. Nesse caso, será necessário mapear o território. A questão não será o domínio dos parágrafos, mas das grandes regiões: introdutória, central e conclusiva; suas áreas, zonas, passagens, trechos e perímetros. Devemos manter a alfabetação e o estabelecimento dos pontos de relações locais, mas também relações globais, entre as grandes regiões e, mais ainda, entre textos e temas. Dependendo da situação, esse processo deve ser praticado com textos variando de 2.000 a 4.000 palavras. É preciso considerar que escritos de não ficção um pouco mais longos deveriam ter lugar central no Ensino Médio.

\section{PRÁTICA II. AS PARTES: EM BUSCA DA UNIDADE PERDIDA}

Para esta segunda prática, selecionamos uma resenha jornalística: "Os Mutantes vão do genial ao nem tanto em sete CDS" de Meneses (2014). Antes da aula, o procedimento é de recorte dos parágrafos. Dessa vez, nosso leitor-aluno terá os parágrafos "embaralhados" fora da linearidade gráfica da resenha. Eles podem ser apresentados em um envelope. O trabalho é então buscar a ordem da unidade gráficolinear perdida. Ou seja, o leitor tem frases, períodos e parágrafos, mas não tem a sequência linear mais ampla das páginas.

Com isso, o leitor é colocado diante das diferenças que constituem a textualidade, mas se depara com o problema da quebra da linearidade. Qual é o primeiro parágrafo? E o último? Que parágrafos constituem a introdução? E as diferentes áreas da região central? Para responder a essas perguntas, o aluno-leitor se deparará com o fundamento da textualidade: "as relações de sentido entre diferenças". Nessas condições, é novamente levado à posição de leitura autoral já que é preciso interferir na textualidade. O que está em questão é o caráter visual da escrita. 


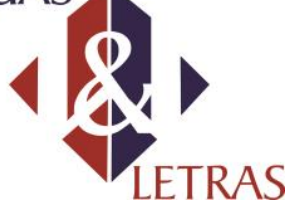

e-ISSN: $1981-4755$

DOI: $10.5935 / 1981-4755.20170004$

Note-se que em ambas as práticas o que está em operação são sentidos de procura, de busca, que afetam e mobilizam o sujeito, isto é, nesse "jogo", estamos diante do próprio da constituição da autoria nas relações da língua com a escrita enquanto interface gráfica e instrumento analítico (numeração das linhas, alfabetação dos parágrafos, outras demarcações). Além disso, a escrita marca os pontos de relação local entre os parágrafos. Com isso, já nesse início do curso, é possível mover algumas discussões sobre características fundamentais da textualidade.

\section{CONSIDERAÇÕES FINAIS}

Há um longo caminho nas atividades de pesquisa voltadas para a identificação e solução de problemas do ensino-aprendizagem da leitura e da escrita em língua portuguesa no Brasil. Nessa direção, observemos que é decisivo que a formação do professor de Letras seja construída na direção efetiva de sua autonomia. Isso significa que ele deve estar em condições teórico-metodológicas para refletir sobre o processo de ensino-aprendizagem. E parte dessa sua reflexão deve estar ao alcance de seu aluno. Claro, o leitor-escritor em formação é, assim, deslocado do "baixo grau de letramento e que teriam como marca a ausência de autoria, fato que coloca o sujeito do discurso como totalmente perdido no grande Outro" (TFOUNI, op. cit., p. 220). Ou seja, é preciso replicar os procedimentos para que as relações próprias do evento-aula toquem os domínios da criatividade tão necessária à experiência da produção do conhecimento.

De forma que é possível e preciso ampliar às discussões em torno dos pontos elementares dos problemas detectados e mobilizar a formação a refletir, bibliograficamente, é claro, e encontrar soluções efetivas.

\section{REFERÊNCIAS}

AUROUX, Sylvain. A Revolução Tecnológica da Gramatização. Campinas, SP: Unicamp, 1992.

. A filosofia da linguagem. Campinas, SP: Editora da Unicamp, 1998.

BALDINI, Lauro. "A NGB e a autoria do discurso gramatical brasileiro". In: Guimarães, Eduardo \& Orlandi, Eni. (org.). Revista Línguas e Instrumentos linguísticos. Campinas, SP: Pontes, 1998.

BAKHTIN, Mikhail. Estética da criação verbal. Tradução de Ermantina G. G. Pereira. São Paulo, SP, Martins Fontes, 1992.

BENVENISTE, Émile. (1966) Problemas de Linguística Geral I. Campinas, SP: Pontes, 1995. (1974) Problemas de Linguística Geral II. Campinas, SP: Pontes, 1989. 


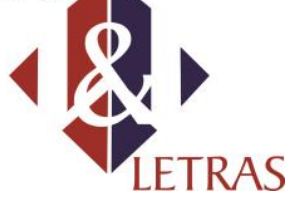

e-ISSN: $1981-4755$

DOI: $10.5935 / 1981-4755.20170004$

BRASIL, Secretaria de Educação Fundamental. PCN: língua portuguesa. Brasília, DF: 1997.

BRONCKART, Jean-Paul. Atividade de linguagem, textos e discursos - por um interacionismo sócio-discursivo. Tradução Anna Rachel Machado e Péricles Cunha. São Paulo, SP: EDUC, 1997.

CARVALHO, Marcos. J. M. de. "Faces da escravidão: a escravidão no Brasil, na América Latina e na África”. In: Jornal de Resenhas. São Paulo, 2004. Disponível em: $<$ http://www.jornalderesenhas.com.br/acervo-jr/ >

CARVALHO, Marcelo. S. R. M. A trajetória da Internet no Brasil: do surgimento das redes de computadores à instituição dos mecanismos de governança. 2006. 239f.

(Mestrado em engenharia de sistemas e computação) - Universidade Federal do Rio de Janeiro, RJ. Disponível em < http://www.nethistory.info/Resources/Internet-BRDissertacao-Mestrado-MSavio-v1.2.pdf >.Marcelo Sávio Revoredo Menezes de Carvalho COIMBRA, Oswaldo. O Texto da Reportagem Impressa. São Paulo, SP: Ática, 1993. DUCROT, Oswaldo. O Dizer e o dito. Campinas, SP: Pontes, 1987.

Princípios de semântica Linguística. São Paulo, SP: Cultrix, 1972.

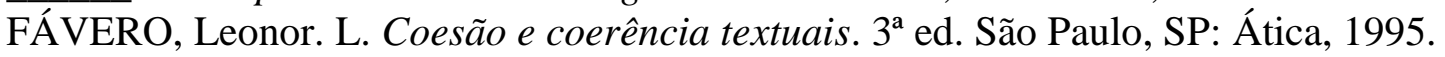

FIAD, R. S. Ensino e autoria. In: TFOUNI, L. V. (org.). Múltiplas faces da autoria. Ijuí: Editora Unijuí, 2008. PP. 2017-236.

GADET, F. \& HAK, T. Por uma análise automática do discurso, uma introdução à obra de Michel Pêcheux. Campinas, SP: Editora da Unicamp, 1997.

GARCIA, OThon. M. (1931) Comunicação em prosa moderna. Rio de Janeiro, RJ: FGV, 1988.

GUIMARÃES, Eduardo. Texto e argumentação: um estudo de conjunções do português. Campinas, SP: Pontes, 1987.

História e sentido na linguagem. Campinas, SP: Pontes, 1989.

Os limites do sentido: um estudo histórico e enunciativo da linguagem.

Campinas, SP: Pontes, 1995.

KOTCHO, Ricardo. A Prática de Reportagem. São Paulo, SP: Ed. Ática, 1986.

FOUCAULT, Michel. A arqueologia do saber. Rio de janeiro, RJ: Forense, 2004.

(1969) O que é um autor? Trad. António F. Cascais e Eduardo Cordeiro. $6^{\mathrm{a}}$ ed.

Lisboa: Nova Vega, 2006.

GERALDI, João. W. Portos de Passagem. $4^{\mathrm{a}}$ ed. São Paulo, SP: Martins Fontes, 1997.

ILARI, Rodolfo. Gramática do Português falado. Campinas, SP: Editora da Unicamp, 2002.

KLEIMAN, Ângela. (org.). Os significados do letramento: uma nova perspectiva sobre a prática social da escrita. Campinas, SP: Mercado de Letras. 1995.

KOCH, Ingedore, G. V. Linguística textual: introdução. São Paulo, SP, Cortez, 1994. "Linguística textual: retrospecto e perspectiva". In: Brait, Beth. Estudos enunciativos no Brasil: histórias e perspectivas. Campinas, SP: Pontes, 2001.

KOCH, I. \& MARCUSHI, Luiz, A. "Processos de Referenciação na Produção Discursiva" In: DELTA vol.14, São Paulo 1998. Disponível em <http://dx.doi.org/10.1590/S0102-44501998000300012>

MARCUSCHI, Luiz. A. Da fala para a escrita: atividades de retextualização. São Paulo, Cortez, 2001.

. "Linearização, cognição e referência: o desafio do hipertexto". In: Língua e

instrumentos linguísticos. Campinas, SP, Pontes, 1999. 1999. Disponível em:

$<$ http://www.pucsp.br/ fontes/ln2sem2006/17Marcus.pdf >. Acesso em: 20 de dez. de 2012. 


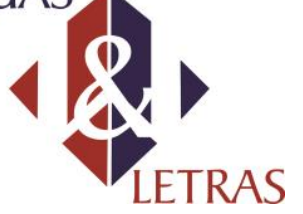

e-ISSN: $1981-4755$

DOI: $10.5935 / 1981-4755.20170004$

MENEZES, Thales. "Os Mutantes vão do genial ao nem tanto em sete CDS". Folha de São Paulo, 08 de agosto de 2014.

ORLANDI, E. A linguagem e seu funcionamento. São Paulo, SP: Martins Fontes, 1985. . Discurso e leitura. São Paulo, SP: Cortez, 1988.

PAIVA, Vera. L. O. SILVA, Marina. M. S \& GOMES, Iran. F. A. "Sessenta anos de linguística aplicada: de onde viemos e para onde vamos" In: PEREIRA, R.C.; ROCA, P. Linguística Aplicada: um caminho com diferentes acessos. São Paulo, SP: Contexto, 2009. Também disponível em: http://www.veramenezes.com/linaplic.pdf

PÊCHEUX, Michel. Semântica e discurso: uma crítica à afirmação do óbvio. Trad. Eni P. Orlandi et all. Campinas: Editora da UNICAMP, 1998.

PIZA, Daniel. Jornalismo Cultural. São Paulo: Contexto, 2003.

POSSENTI, Sírio. Por que (não) ensinar gramática na escola. Campinas, SP: Mercado de letras, 1996.

. "Indícios de autoria". Perspectiva - Revista do Centro de Ciências da Educação. Florianópolis, SC: Editora da UFSC, 20 (1), p. 105-124, 2002.

MORENO, Cláudio. Curso básico de redação. São Paulo, SP, Editora Ática, 2009.

MELO, José Marques de. A opinião do jornalismo brasileiro. Petrópolis, RJ: Vozes, 1985.

ORLANDI, E. Discurso e texto: formulação e circulação dos sentidos. Campinas, São Paulo, SP: Pontes, 2001.

REBOUL, Oliver. O Slogan. São Paulo, SP: Cultrix, 1975.

SEVERINO, Antônio. J. Metodologia do trabalho científico. $21^{\mathrm{a}}$ ed. rev. e ampl. São Paulo, SP, 2000.

TFOUNI, Leda. V. (org.). Múltiplas faces da autoria. Ijuí: Editora Unijuí, 2008. . Letramento e Alfabetização. São Paulo, Cortês, 2010.

VOGT, Carlos. $O$ intervalo semântico: contribuição para uma teoria semântica argumentativa. São Paulo, SP: Ática, 1977.

Linguagem, pragmática e ideologia. São Paulo, SP: Hucitec; Campinas, SP: Funcamp, 1980.

Data de recebimento: 30/11/2016

Data de aprovação: 17/05/2017 